\title{
Wear Studies on Phenolic Brake-Pads Using Taguchi Technique
}

\author{
F.F. Yusubova,* \\ a Department of Mechanics, Azerbaijan State Oil and Industry University, Baku, Azerbaijan.
}

Keywords:

Wear

Composites

Brake-pads

Taguchi

ANOVA

Modeling

Optimization

* Corresponding author:

F.F. Yusubov

E-mail: fikratyusub@gmail.com

Received: 21 December 2020

Revised: 2 February 2021

Accepted: 24 March 2021

\begin{abstract}
A B S T R A C T
The present work considers wear performance of non-asbestos organic (NOA) brake-pad composite materials. The specimens were manufactured by conventional Powder Metallurgy Methods. The experiments was carried out in dry condition on universal MMW-1 tribometer by pin-on-disc configuration. Tests were conducted based on plan L27 orthogonal array generated through Taguchi technique and mathematical model were developed. The criteria "smaller-is-better" selected to examine the dry sliding behavior of developed composite materials. The wear rate and process variables (contact pressure, sliding velocity and cycles) were examined by analysis of variance (ANOVA) method using Minitab 19.1.1 software. Worn surface examination of the brake-pad materials was done using scanning electron microscope (SEM). The strongest influence on the wear rate was exhibited by the sliding velocity (52.61\%), then follow contact pressure (30.47\%) and the cycles (16.01\%). The studies based on prediction and optimization concluded with confirmation tests.
\end{abstract}

\section{INTRODUCTION}

Today's modern trend in the tribology industry requires the development of new ecologically clean and sustainable materials. The safety of brake system is determining whole performance of tribological applications [1]. Effective brake performance depends mainly on wear mechanism and friction properties of contacting materials [2]. Brake material must have important features such as high coefficient of friction, low wear rate, high heat dissipation rate, and dimensional stability at high temperatures
[3]. Despite the fast progress of manufacturing technologies, wear has always been one of the main problems for brake pad materials. The generated heat during friction process under various conditions are resulting with wear of materials [4]. The tribological properties of the brake material are closely related to the surface worn [5]. Worn surface usually characterized by material removal, surface deformation and friction layer formation. Consequently, intensive wear and changes on contact surface morphology can also reduce friction coefficient. As in recent years, because of its heat resistant and good 
mechanical properties asbestos has used as major constituent for friction materials. Nevertheless, due environmental and health concerns, use of asbestos has banned in many countries. As safety and ecological concerns around the world increase, the role of polymerbased, organic materials has increased even more [6]. The reason for the widespread use of polymeric materials was their low weight, excellent physical-mechanical characteristics and simple processing properties [7].

Due complexity of wear phenomena systematic approach needs to comprehensively study tribological properties of friction couples. Design of experiment (DOE) one of the most significant statistical technique to study various process parameters by reducing the number of multiple experiments. Taguchi approach is powerful design tool for controlling quality characteristics [8]. The Taguchi technique offers very useful elements for conducting experiments such as signal-to-noise (S/N) ratio and "smaller-isbetter", "larger-the-better" or "nominal-thebetter" criterias [9]. Brake-pads materials are mainly influenced by the following braking parameters: load, sliding velocity and distance, surface conditions and etc. Considerable number of research works has dedicated to analysis wear behavior of different non-asbestos organic (NOA) friction composites for braking systems using DOE methods. In many cases by these studies, pressure shown as most influential parameter for friction and wear.

Sudeepan, et al., 2014 investigated and reported that most influential factor which is affecting specific wear rate is load for polymer matrix composites [10]. The analyzing wear behavior of the SiC reinforced epoxy polymer composites using Taguchi methods showed that load predominantly influencing the wear characteristics beside material factor (Madhusudhan et., all 2017) [11]. Kahraman, et al., 2019 also analyzed NOA brake friction materials using Taguchi and Response Surface Methodology and reported that the percentage contribution for braking pressure is $99.28 \%$ [12]. The same tendency also was observed by Dhanalakshimi, et al., 2018, while investigating tribological behavior of metal matrix composites [13]. This effect explained by the temperature rise at the interface between the disc and pin with increasing of the applied load. The literature survey, showed that load or contact pressure is the most important factor influencing the wear process. However, it should be noted that the effects of factors may be different depending on the compositions and their proportion. While there are many literature studies presented for the wear behaviour of polymer-based NOA friction composites but most of the research work based on performance of brake pads. Only few of these works presented optimization of weight loss of the brake composite in wear process, especially for heavy loading conditions.

This study is focused on to attain optimized maximal low wear rates and determining influences of important factors and wear mechanisms which are defines tribological behavior of brake materials like contact pressure, sliding velocity and cycles. The brake-pads material used in this work was prepared based on an NOA type formulation. The wear performance of new type phenolic resin friction composite was investigated to identify the effect of design parameters and predict the wear behaviour.

\section{FABRICATION OF SPECIMENS}

In this work, the brake pad composite materials produced by following formulations: $25 \%$ barite, 25\% phenolic resin (modified by $\mathrm{N}$ Methylaniline), $\quad 10 \%$ lead, $7 \%$ aluminum dioxide, $\quad 10 \%$ tin, $7 \%$ copper-graphite $(80 \% \mathrm{Cu} 20 \% \mathrm{C}), \quad 5 \%$ silicon dioxide, $2 \%$ molybdenum disulfide, $5 \%$ wollastonite and $2 \%$ magnesium oxide. Besides, $2 \%$ brass chips also were used in composition as reinforcing element and for improving heat conductivity. The Fig.1 shows the sequence of preparation of friction composites and appearance of powder components at different stages. Sample materials were manufactured by a traditional procedure for solid-state formulation following ball milling, mechanical mixing (for 16 hours with speed of 60 cycles/min on a horizontal drum mixer), pre-forming $(10 \mathrm{MPa})$, hot pressing $\left(160^{\circ} \mathrm{C}, 25,5 \mathrm{MPa}\right)$ and post curing (for 5 hours in $140^{\circ} \mathrm{C}$ ) in a muffle furnace.

Ball milling was carried out in a vibrating laboratory ball mill (ML-1) equipment for 12 hours. Size of balls were $12 \mathrm{~mm}$. Particles average size of were $50 \mu \mathrm{m}$ for all composition ingredients. Specimens were molded in steel die. 


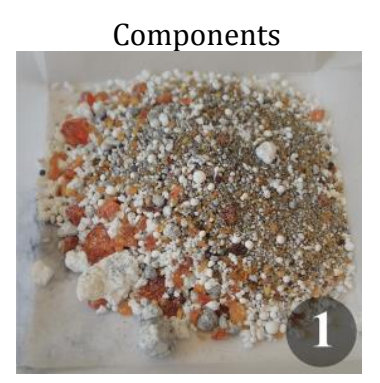

Mixing

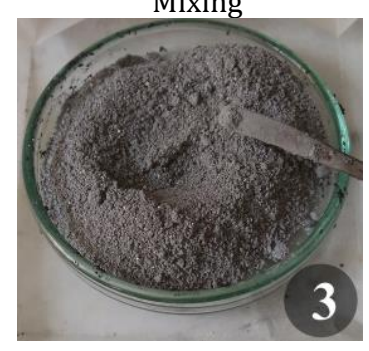

Ball milling

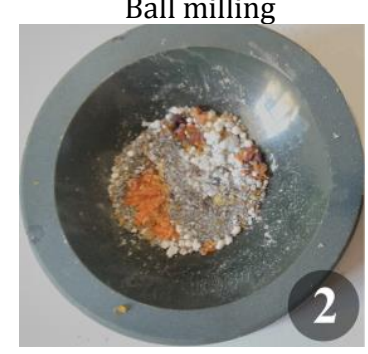

Hot-pressing

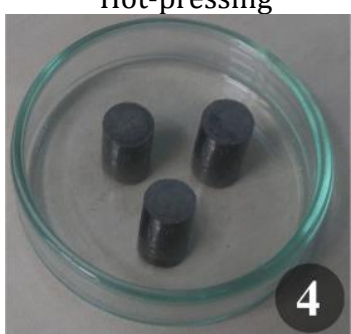

Fig. 1. Appearance of powder components at different stages of manufacturing process.

\section{DESIGN OF EXPERIMENTS}

In this study, in order to analyze of effect control factors and interactions on wear properties Taguchi approach (developed by Taguchi G. and Konishi S. 1987) was used. Taguchi method based on orthogonal arrays and in contrast to the traditional experimental design methods it designed for the simultaneous modelling of both means and variability [9].

The DOE was conducted mainly in five stages for estimating quality characteristics: S/N calculation, analysis of variance (ANOVA) statistical analysis, obtaining linear regression model \& checking adequacy of the model, optimization process parameters, confirmation test. The selection of design parameters was done in order of covering a commonly applied operating regime for industrial applications. Contact pressure and sliding velocity are commonly regarded as the main factor in defining wear rate [14]. The first parameter was assigned contact pressure (A), second sliding velocity (B) and third cycles (C). The cycles show the total number of revolutions of the disc during friction. Levels of input factors were determined by testing analog material (widely used asbestos brake pad composite "Retinax B" (FK-24A): GOST 10851-94) under laboratory conditions. Selected factors and levels for each parameter are summarized in Table 1.
Table 1. Levels of various process parameters.

\begin{tabular}{|c|c|c|c|c|c|}
\hline $\begin{array}{c}\text { Control } \\
\text { factors }\end{array}$ & Code & Unit & $\begin{array}{c}\text { Level } \\
\text { I }\end{array}$ & $\begin{array}{c}\text { Level } \\
\text { II }\end{array}$ & $\begin{array}{c}\text { Level } \\
\text { III }\end{array}$ \\
\hline $\begin{array}{c}\text { Contact } \\
\text { pressure }\end{array}$ & $\mathrm{A}$ & $\mathrm{MPa}$ & 1.9 & 5.75 & 9.6 \\
\hline $\begin{array}{c}\text { Sliding } \\
\text { velocity }\end{array}$ & $\mathrm{B}$ & $\mathrm{m} / \mathrm{s}$ & 0.64 & 1.57 & 2.5 \\
\hline Cycles & $\mathrm{C}$ & $\mathrm{n}$ & 10000 & 20000 & 30000 \\
\hline
\end{tabular}

The three level L27 orthogonal array was selected to design the experimental plan (Table 2).

The orthogonal array and $\mathrm{S} / \mathrm{N}$ ratios are main tools in Taguchi technique [15]. $\mathrm{S} / \mathrm{N}$ ratios determines how the output values varies relative to the selected target value under different noise factors (uncontrollable factors) [16]. Taguchi designs identify control factors that minimize the effect of the noise factors. The "signal" represents the desirable target for the process [17]. In order to find the optimal regimes and minimize wear, $\mathrm{S} / \mathrm{N}$ ratios was calculated according to "smaller-the-better" criterion (Phillip J. Ross, 1988):

$$
\frac{S}{N}=-10 \log \left[\frac{1}{n} \sum_{i=1}^{n} y_{i}^{2}\right]
$$

where $\mathrm{y}$ is observed data for the given input level, $\mathrm{n}$ is number of experiments. Each factor level combination was repeated three times and obtained average test results was used on data evaluating.

\section{DRY SLIDING WEAR TEST}

The dry sliding wear tests were conducted on universal vertical MMW-1 tribometer with "pin-ondisc" configuration at ambient room temperature. The principle of tests is based on the simultaneous clockwise rotating of three cylindrical pin specimens on a stationary disc. The friction moment was recorded every second and obtained data automatically transferred to a computer. A schematic diagram of pin-on-disc contact configuration was shown in the Fig. 2. The quenched steel disc with hardness: 44-46 HRC and surface roughness: $\sim 0.2 \mu \mathrm{m}$ was used as the counter-face material. The cylindrical pins were in size of $4.7 \mathrm{~mm}$ diameter and $13 \mathrm{~mm}$ height. The contact area of the three samples with the disc was approximately $52 \mathrm{~mm}^{2}$. The wear rate was calculated with this formula:

$$
J=\frac{m_{1}-m_{2}}{\tau}
$$


where $\mathrm{J}$ is wear rate $[\mathrm{g} / \mathrm{hour}], \mathrm{m}_{1}$ and $\mathrm{m}_{2}$ are the mass before and after wear respectively [gram] and $\tau$ is the duration of the experiment [hours]. Specimens were weighed before and after friction tests on an electronic balance (Mettler Toledo) with an accuracy of $\pm 0.1 \mathrm{mg}$.

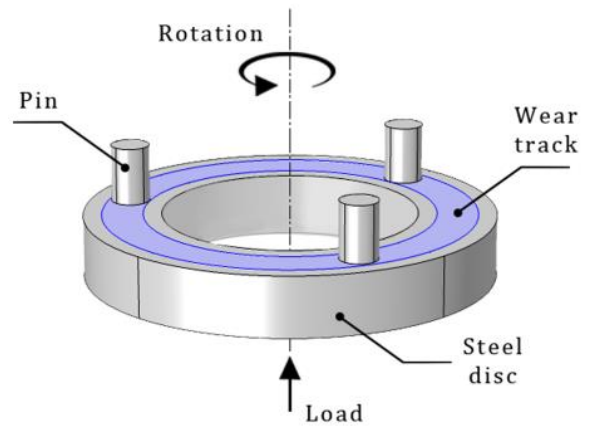

Fig. 2. Schematic of pin-on-disc configuration.

\section{RESULTS \& DISCUSSION}

The effect of design parameters and its combinations on wear process for the NOA friction composite materials are investigated through
Taguchi methodology. The ANOVA test, SEM examination and wear mechanisms of the prepared composite materials has been discussed in detail.

\subsection{Statistical analysis of experiments}

It is known that the wear behavior of composites directly depends on the nature of the friction process. During the sliding tests performed on the basis of the selected orthogonal matrix, it was determined that the coefficient of friction varied between $0.367-0.445$ for the prepared samples.

The results of wear tests based on planning matrix are given in Table 2. Along with average wear rate values, standart deviations (St Dev) for the repeated test also was presented. As the per orthogonal array for each row the obtained measurement values of wear rate are transformed in $\mathrm{S} / \mathrm{N}$ ratio. In order to define influence of control parameters $\mathrm{S} / \mathrm{N}$ ratio calculation are playing important role [18]. The highest wear rate $(0.068$ $\mathrm{g}$ /hour) was observed at the third level of each factor: $9.6 \mathrm{MPa}$ contact pressure, $2.50 \mathrm{~m} / \mathrm{s}$ sliding velocity and 30000 cycles.

Table 2. Results of experiments based on L27 ( $\left.3^{3}\right)$ orthogonal array.

\begin{tabular}{|c|c|c|c|c|c|c|}
\hline № & $\begin{array}{c}\text { Contact } \\
\text { pressure [MPa] }\end{array}$ & $\begin{array}{c}\text { Sliding } \\
\text { velocity }[\mathrm{m} / \mathrm{s}]\end{array}$ & Cycles, $\mathbf{n}$ & $\begin{array}{l}\text { Wear rate } \\
\text { [g/hour] }\end{array}$ & St Dev & $\mathrm{S} / \mathrm{N}$ ratio $[\mathrm{dB}]$ \\
\hline 1. & 1.9 & 0.64 & 10000 & 0.003 & 0.000433013 & 50.4576 \\
\hline 2. & 1.9 & 0.64 & 20000 & 0.009 & 0.001118034 & 40.9151 \\
\hline 3. & 1.9 & 0.64 & 30000 & 0.013 & 0.001224745 & 37.7211 \\
\hline 4. & 1.9 & 1.57 & 10000 & 0.019 & 0.00147902 & 34.4249 \\
\hline 5. & 1.9 & 1.57 & 20000 & 0.025 & 0.000433013 & 32.0412 \\
\hline 6. & 1.9 & 1.57 & 30000 & 0.032 & 0.001089725 & 29.8970 \\
\hline 7. & 1.9 & 2.5 & 10000 & 0.039 & 0.00163936 & 28.1787 \\
\hline 8. & 1.9 & 2.5 & 20000 & 0.046 & 0.001224745 & 26.7448 \\
\hline 9. & 1.9 & 2.5 & 30000 & 0.053 & 0.000707107 & 25.5145 \\
\hline 10. & 5.75 & 0.64 & 10000 & 0.012 & 0.001089725 & 38.4164 \\
\hline 11. & 5.75 & 0.64 & 20000 & 0.019 & 0.001870829 & 34.4249 \\
\hline 12. & 5.75 & 0.64 & 30000 & 0.027 & 0.0005 & 31.3727 \\
\hline 13. & 5.75 & 1.57 & 10000 & 0.024 & 0.002046338 & 32.3958 \\
\hline 14. & 5.75 & 1.57 & 20000 & 0.032 & 0.000866025 & 29.8970 \\
\hline 15. & 5.75 & 1.57 & 30000 & 0.040 & 0.001224745 & 27.9588 \\
\hline 16. & 5.75 & 2.5 & 10000 & 0.034 & 0.001785357 & 29.3704 \\
\hline 17. & 5.75 & 2.5 & 20000 & 0.043 & 0.001581139 & 27.3306 \\
\hline 18. & 5.75 & 2.5 & 30000 & 0.052 & 0.000433013 & 25.6799 \\
\hline 19. & 9.6 & 0.64 & 10000 & 0.029 & 0.000829156 & 30.7520 \\
\hline 20. & 9.6 & 0.64 & 20000 & 0.035 & 0.002487469 & 29.1186 \\
\hline 21. & 9.6 & 0.64 & 30000 & 0.042 & 0.00147902 & 27.5350 \\
\hline 22. & 9.6 & 1.57 & 10000 & 0.036 & 0.003082207 & 28.8739 \\
\hline 23. & 9.6 & 1.57 & 20000 & 0.044 & 0.001089725 & 27.1309 \\
\hline 24. & 9.6 & 1.57 & 30000 & 0.054 & 0.00147902 & 25.3521 \\
\hline 25. & 9.6 & 2.5 & 10000 & 0.047 & 0.002277608 & 26.5580 \\
\hline 26. & 9.6 & 2.5 & 20000 & 0.057 & 0.000707107 & 24.8825 \\
\hline 27. & 9.6 & 2.5 & 30000 & 0.068 & 0.003191786 & 23.3498 \\
\hline
\end{tabular}


The ranking of control factors using $\mathrm{S} / \mathrm{N}$ ratio calculation for various level parameters based on wear rate are given in Table 3 . Where delta $(\Delta)$ is the average difference between the maximum and minimum output data for each design factor.

Table 3. Response table for $\mathrm{S} / \mathrm{N}$ ratios for wear rate.

\begin{tabular}{|c|c|c|c|}
\hline Level & $\begin{array}{c}\text { Contact } \\
\text { pressure }\end{array}$ & $\begin{array}{c}\text { Sliding } \\
\text { velocity }\end{array}$ & Cycles \\
\hline 1 & 33.99 & 35.63 & 33.27 \\
\hline 2 & 30.76 & 29.77 & 30.28 \\
\hline 3 & 27.06 & 26.40 & 28.26 \\
\hline Delta $(\Delta)$ & 6.93 & 9.23 & 5.01 \\
\hline Rank & 2 & 1 & 3 \\
\hline
\end{tabular}

Taguchi suggests that output values with a large $\mathrm{S} / \mathrm{N}$ ratio indicates its the importance on the process. In accordance with the analysis of the $\mathrm{S} / \mathrm{N}$ ratio, most important factors influencing the process have been determined (as shown in Fig. 3 ). It was found that sliding velocity was most significant input parameter affecting wear rate, followed by contact pressure and cycles. Further, the obtained experimental results by chosen orthogonal array were analyzed by ANOVA using Minitab 19.1.1 software. ANOVA was applied to determine the relative importance of the design parameters affecting the wear process.

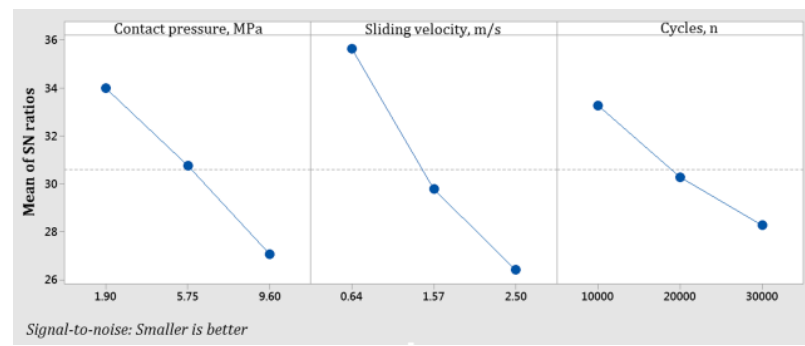

Fig. 3. Main effect plot (data means) for the wear rate.

Table 4 shows the ANOVA results for the wear rate which is performed at 95\% level of confidence (i.e. $5 \%$ level of significance). Where DF is the degrees of freedom, Seq SS is the sequential sum of squares, Adj SS is the adjusted sum of squares and $P$ is the percentage of contribution. $F$ ratios were taken into account to identify the significance level of the factors and its combinations (Table 4). It is observed from main effect plots (Fig. 3) that the sliding velocity with the $52.61 \%$ percentage contribution $(\mathrm{P})$ is the most influential factor for the wear. Followed by contact pressure $(30.47 \%)$ and the cycles $(16.01 \%)$. The combination of contact pressure*sliding velocity $\left(A^{*} B\right)$ was the most statistically significance parameter among interaction factors $(3.50 \%)$.

The percentage of contribution for the contact pressure* ${ }^{*}$ cycles $\left(\mathrm{A}^{*} \mathrm{C}\right)$ and sliding velocity*cycles $\left(B^{*} \mathrm{C}\right)$ combinations were $0.33 \%$ and $0.29 \%$, respectively. In Fig. 3 contour plot for dependence between wear rate and main control factors are given. Overall, the interaction between contact pressure and sliding velocity most dominant setting for wear rate. Before 3.0 $\mathrm{MPa}$ contact pressure no drastically wear observed. The slightest wear was observed in lower levels of the control factors, respectively A1 (1.9MPa), B1 (0.64 m/s) and C1 (10000).
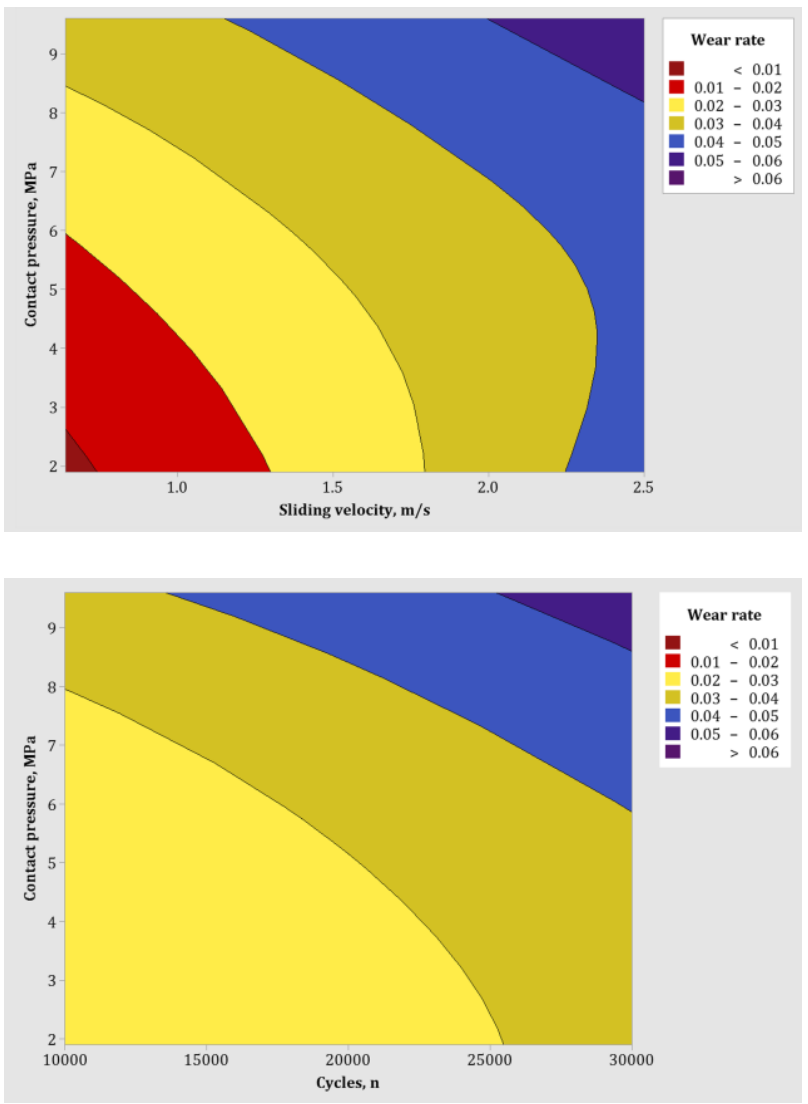

Fig. 4. Contour plot for dependence between wear rate and control factors.

However, if we look carefully, at the results presented in Table 2, high wear rates can be observed even lowest contact pressure (A1) regimes. The increase in wear rate on lowest contact pressure may be attributed to the interaction between control factors. The interaction between the design parameters is presented in Fig. 5. 
Table 4. Analysis of variance (ANOVA) table for wear rate.

\begin{tabular}{|c|c|c|c|c|c|c|c|}
\hline Source & DF & Seq SS & Adj SS & Adj MS & F-value & P-value & P, $\mathbf{\%}$ \\
\hline $\mathrm{A}$ & 2 & 0.001797 & 0.001797 & 0.000898 & 1515.81 & & $27.18 \%$ \\
\hline $\mathrm{B}$ & 2 & 0.003477 & 0.003477 & 0.001738 & 2933.69 & & $52.61 \%$ \\
\hline $\mathrm{C}$ & 2 & 0.001058 & 0.001058 & 0.000529 & 892.94 & & $16.01 \%$ \\
\hline $\mathrm{A}^{*} \mathrm{~B}$ & 4 & 0.000231 & 0.000231 & 0.000058 & 97.47 & & $3.50 \%$ \\
\hline $\mathrm{A}^{*} \mathrm{C}$ & 4 & 0.000022 & 0.000022 & 0.000005 & 9.16 & 0.004 & $0.33 \%$ \\
\hline $\mathrm{B}^{*} \mathrm{C}$ & 4 & 0.000019 & 0.000019 & 0.000005 & 8.13 & 0.006 & $0.29 \%$ \\
\hline Error & 8 & 0.000005 & 0.000005 & 0.000001 & & & $0.07 \%$ \\
\hline Total & 26 & 0.006609 & & & & & $100.00 \%$ \\
\hline
\end{tabular}

Fig. 5 shows that there is difference beetwen sliding velocity (A) and contact pressure (B) interaction. It can be seen from plots that the wear rate increases significantly with increasing contact pressure, especially when sliding velocity is $2.50 \mathrm{~m} / \mathrm{s}$. The difference shows itself more when comparing with other interaction, for example with contact pressure and cycles. This relationship can be explained by physical-mechanical properties of contacting pair materials. It is known that, contact pressure can influence to wear mechanism with changing actual contact area and formation of friction films [19].

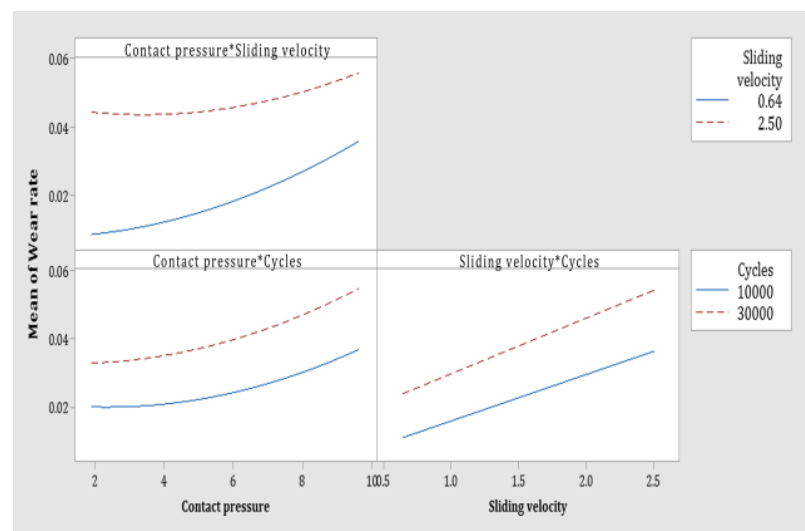

Fig. 5. Interaction plot of design parameters for wear rate.

As can be seen in Fig. 3 and 5, when the sliding velocity is $0.64 \mathrm{~m} / \mathrm{s}$, the mean wear rate under different contact pressures has general trend with the gradually increase of wear. Fig. 6 exhibits area graph of wear rate. Area graph was divided to three part, depending on start and end partition of each level for contact pressure (A1, A2, A3).

As can be seen from graphs after starting each partition wear rate decreaces rapidly and as test continues wear rate increases comparatively (№1-9 < №10-18 < №19-27). The main reason for this is sliding velocity. Despite of gradually increase of wear depending on contact pressure, for $2.50 \mathrm{~m} / \mathrm{s}$ sliding velocity, wear rate increases very quickly at certain point. When contact pressure increases, it leads generating more debris and consequently, developing new friction layer [20]. New friction layer is reducing wear over a period of time. Nevertheless, the increase in contact surface temperature with the increase of sliding velocity is causing the change of surface morphology by wearing. When contact morphology changes more material removal is occurring during the dry wear process [21]. Removed abrasive particles are like aluminum oxide and silicon dioxide causing abrasive wear in friction surface. Therefore, even in low contact pressure regime increasing sliding velocity leads to a further increase in wear rate (Fig. 6 and 4).

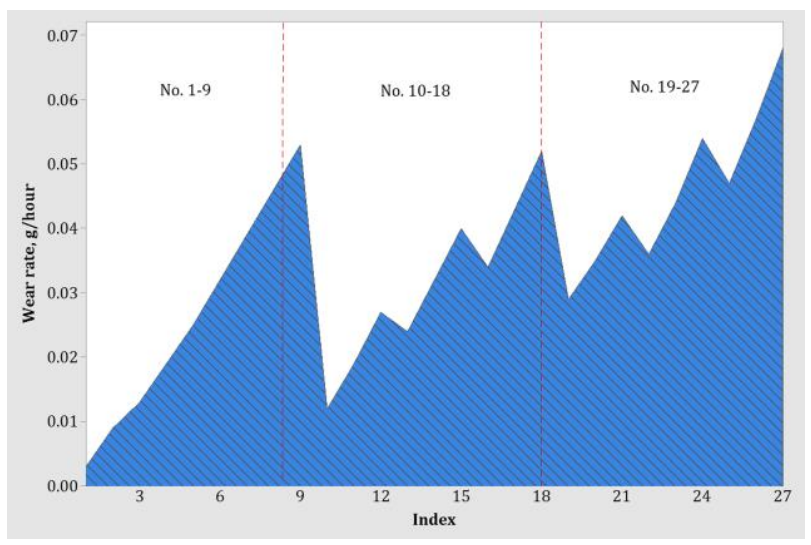

Fig. 6. Area graph of wear rate.

Fig. 7 demonstrates the SEM images of worn surfaces in various testing combinations based on planning matrix. The codes in the SEM images indicate the number of the experiment performed according to the design matrix. As observed from Fig. 7 (№10, 18 and 27) wear debris were more common at high contact pressures (5.75 and 9.6 MPa). An increase in contact pressure causes more heat to be released, which leads to thermal degradation of organic components such as phenolic resin [22]. 

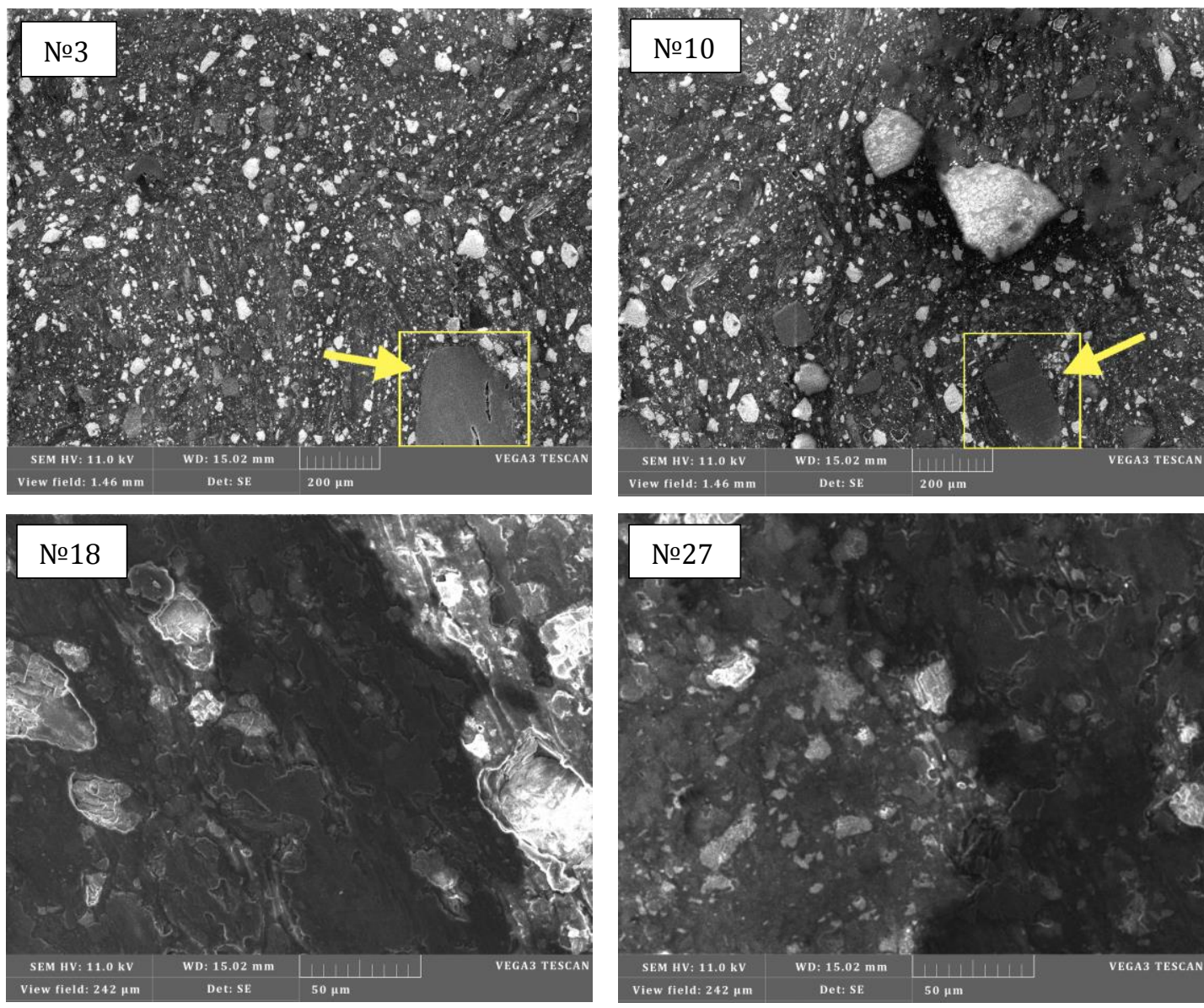

Fig. 7. SEM micrographs of worn surfaces in various testing combinations (test № 3, 10, 18, 27).

Degradation of organic components at temperatures between $200-350^{\circ} \mathrm{C}$ due to frictional heat generated during dry sliding has a significant effect on both friction and wear. The chemical reaction between the hydroxyl and methylene groups of phenol-formaldehyde leads to carbonization at temperatures of $400-600{ }^{\circ} \mathrm{C}$. As a result of this process, the bond between the friction pairs begins to weaken and affects the friction process by changing the contact areas on the surface. Consequently, over a period of time, heat reduces the coefficient of friction and increases wear. As long as the sliding continues, the interaction of the surface with chemically active additives forms a protective film [6]. Thus, it effectively protects the surface from wear if the speed of film formation exceeds the wear rate. Components that have undergone thermal degradation at the contact surface results in material removal and these worn-out components changes into wear debris. In SEM micrographs of №3 and 10 contact plateau can be clearly observed (marked with yellow lines). Trapped and compressed wear debris particles between contacting surfaces under heat forming contact plateau [23]. It suggests that contact plateaus are formed mainly by phenolic resin binder, which have been compacted during friction. As long as the sliding continues, the debris is reduced in size by fragmentation and worn debris particles begin to participate in the formation a of secondary plateaus or leave the friction surface [24]. In addition to wear debris and contact plateau there are some micro-cracks on the contact surface also observed (№18 and 27). Dissipated frictional heat influences to thermal strength and plasticity of the surfaces which eventually leads to plastic deformation [25]. Changes in the microstructure due to increased temperature causes the generation of surface cracks and damage. Thus, formation of micro-cracks ultimately contributes to increased wear rate. When applied load increases the contact pressure between pin and disc surface temperature increases and because of frictional temperature rise material removal also begins to increase. As observed in Table 2, there was an increase of wear rate when sliding velocity is higher. The higher sliding velocity also raises the interfacial temperature due increased friction 
between contact surfaces [26]. Therefore, increase in sliding distance also serves to increase wear rate. As can be seen from SEM images (Fig. 7, №18, 27) there is micro-voids in worn surfaces. During repeated cycles due falling metallic particles like aluminum dioxide are causing the formation of micro-voids [27]. This also indicates the participation of metal particles in the friction played important role on wearing process.

\subsection{Modelling and optimization}

The factors considered in the tests are optimized to attain maximal low wear rates. Based by ANOVA results, a linear regression equation was applied to establish a correlation between the significant term conditions, and the following equation was fitted for the wear rate:

$$
\begin{gathered}
J=-0.02046+0.003564 A+0.01854 B \\
-0.001094 A * B
\end{gathered}
$$

From shown equation it is observed that sliding velocity play a major role on wear rate followed by contact pressure. Obtained regression equation can be used to predict wear behaviour of the brake pad specimen. The positive values of $A$ and $B$ terms are indicating that increase in contact pressure and sliding velocity increases the wear rate. The interaction $A^{*} B$ indicates a decrease in wear rate. Information about the coefficients related to the model can be found in Table 5. The model summary for the obtained regression equation is $\mathrm{S}=0.0031144, \mathrm{R}^{2}=97.06 \%$ and $\mathrm{R}^{2}(\mathrm{adj})=97.06 \%$.

Table 5. The coefficients of regression equation.

\begin{tabular}{|c|c|c|c|c|}
\hline Term & Coef & SE Coef & T-value & P-value \\
\hline Constant & 0.43021 & 0.00827 & 52.05 & \\
\hline $\mathrm{A}$ & 0.00420 & 0.00102 & 4.11 & 0.001 \\
\hline $\mathrm{B}$ & -0.01756 & 0.00405 & -4.33 & \\
\hline $\mathrm{C}$ & -0.000001 & & -2.32 & 0.031 \\
\hline $\mathrm{A}^{*} \mathrm{~B}$ & 0.000861 & 0.00040 & 2.15 & 0.044 \\
\hline $\mathrm{A}^{*} \mathrm{C}$ & & & -1.22 & 0.237 \\
\hline $\mathrm{B}^{*} \mathrm{C}$ & & & -0.93 & 0.364 \\
\hline
\end{tabular}

The results of the optimization for the wear rate are presented in Fig. 8. Where blue lines show optimal setting. Black lines show the predicted wear rate values at different setting.

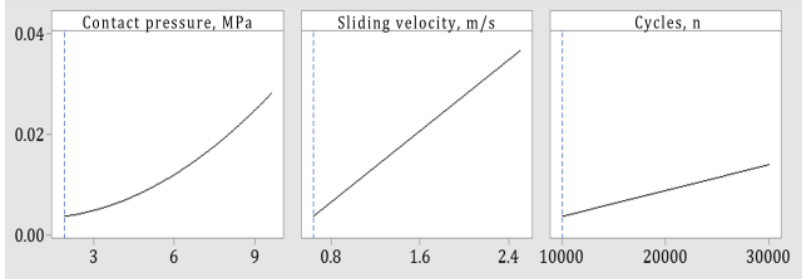

Fig. 8. Optimal setting graphs for wear rate.

Thereby, the optimal wear combination of the brake pad specimen for wear rate was concluded 1.9 MPa for contact pressure, sliding velocity 0.64 $\mathrm{m} / \mathrm{s}$ and 10000 for cycles. For this combination wear rate was $0.0020093 \mathrm{~g} /$ hour. In addition, five alternative optimal regime conditions acquired as a result of the optimization are also given in Table 6.

Table 6. Top five alternative optimal combination for wear rate.

\begin{tabular}{|c|c|c|c|c|}
\hline № & A & B & C & Y \\
\hline 1. & 1.9 & 0.64 & 20000 & 0.00875 \\
\hline 2. & 5.75 & 0.64 & 10000 & 0.0111389 \\
\hline 3. & 1.9 & 0.64 & 30000 & 0.0139167 \\
\hline 4. & 5.75 & 0.64 & 20000 & 0.0175556 \\
\hline 5. & 1.9 & 1.57 & 10000 & 0.0201389 \\
\hline
\end{tabular}

\subsection{Confirmation test}

The experimental results were validated by the confirmation tests. The verification tests are very important in order to support statistically obtained results. For prediction calculations optimal A1, B1, C1 combination was chosen. The predicted value of $\mathrm{S} / \mathrm{N}$ ratio $(\bar{y})$ at the optimal settings was calculated as follows (Roy, 1990):

$$
\bar{y}=y_{m}+\sum_{i=1}^{k}\left(\bar{y}_{i}-y_{m}\right)
$$

where $y_{m}$ is the total mean of $\mathrm{S} / \mathrm{N}$ ratio, $\bar{y}_{i}$ is average $\mathrm{S} / \mathrm{N}$ ratio at the optimal level and $k$ is the number of chosen main design parameters. Optimal wear rate was calucalated $0.0031 \mathrm{~g} /$ hours.

The confidence interval (CI) was carried out to verify the quality characteristics of the confirmation tests. The $\mathrm{CI}$ for the predicted optimal results is calculated with this formula [9, 29]:

$$
C I= \pm \sqrt{F_{\alpha}\left(1, f_{e}\right) \cdot V_{e}\left[\frac{1}{n_{e f f}}+\frac{1}{r}\right]}
$$


where $F_{\alpha}\left(1, f_{e}\right)$ is $\mathrm{F}$ value at a required confidence level of $(1-\alpha), \alpha$ is the significance level, $f_{e}$ is the error degrees of freedom, $r$ is the number of repeated tests and $V_{e}$ is the error variance (ANOVA) [30]:

$$
V_{e}=\frac{S S(\text { pooled of error variance })}{D O F(\text { pooled of error variance })}
$$

where $n_{e f f}$ is total number of the effective replications:

$$
n_{e f f}=\frac{R}{1+T_{D O F}}
$$

where $T_{D O F}$ is total DOF of factors of prediction and $R$ is total number of experimental trials. For the confidence level of $95 \%(\alpha=0.05)$ and $f_{e}=8$ (Table 4), the value is $F_{0.05}(1,8)=5.3177$ (this value tabulated from $\mathrm{F}$-chart). Thus, the $\mathrm{CI}$ was calculated as \pm 0.0019 using above mentioned equations. Considering this, the predicted optimum wear rate is:

$$
\begin{aligned}
& (0.0031-0.0019)<J(g / \text { hour })<(0.0031+0.0019) \\
& 0.0012<J(g / \text { hour })<0.005
\end{aligned}
$$

The predicted value of wear rate by using the levels of the optimal control factors (A1, B1, C1) was in good agreement with the confirmation test (average value of wear rate $=0.0031 \mathrm{~g} /$ hour) and matched within 95\% CI. Fig. 9 exhibits normal probability plots of the predicted and experimental results of wear rate. The obtained regression equation corresponds to the plots given in Fig. 9.

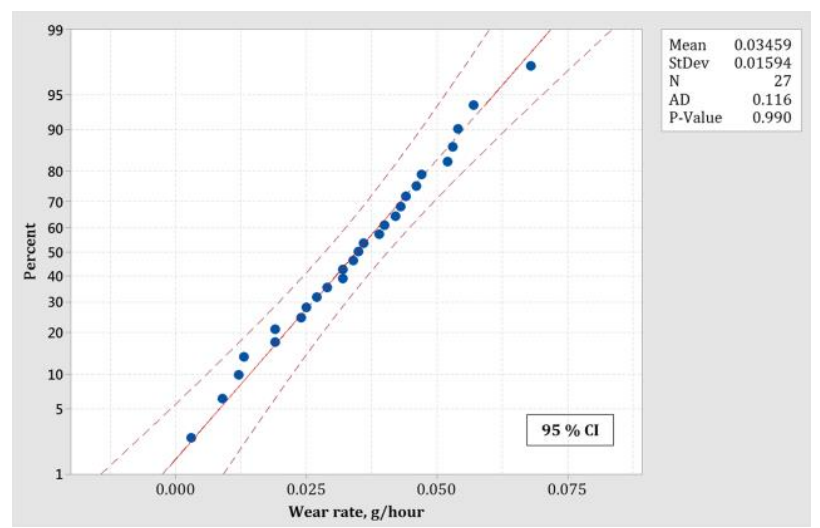

Fig. 9. Normal probability plot for wear rate.

Table 6 show the predicted and confirmation test values of $\mathrm{S} / \mathrm{N}$ ratios at the optimal levels for average wear rate. Results of confirmation test compared to predicted value and also the percentage error is shown in Table 6.
Table 6. Results of the confirmation test.

\begin{tabular}{|c|c|c|c|}
\hline A1, B1, C1 & $\begin{array}{c}\text { Predicted } \\
\text { value }\end{array}$ & $\begin{array}{c}\text { Experimental } \\
\text { value }\end{array}$ & $\begin{array}{c}\text { Error, } \\
\text { \% }\end{array}$ \\
\hline $\begin{array}{c}\text { Wear rate, } \\
\text { g/hour }\end{array}$ & 0.0031 & 0.0030 & 3.23 \\
\hline S/N ratio, dB & 48.3043 & 50.4576 & 4.46 \\
\hline
\end{tabular}

The percentage error between confirmation experiment and prediction is $3.23 \%$. It shows that the model equation presents appropriateness with the experimental result.

\section{CONCLUSIONS}

In the present work, Taguchi technique and ANOVA has used to modeling and optimization of a dry sliding wear behavior of new eco-friendly brakepads composite materials which is manufactured by Powder Metallurgy Methods. The three different design factors, namely, contact pressure, sliding velocity and cycles were considered. Selected parameters were varied at three different levels.

Following are the conclusions can be drawn from this study:

- The ANOVA observation showed that sliding velocity $(52.61 \%)$, is the most significant parameter affecting on wear rate followed by contact pressure (30.47\%) and cycles (16.01\%).

- It was also concluded that even in low contact pressure conditions increase of sliding velocity leads to a further increase in wear rate due abrasive particles like aluminium oxide and silicon dioxide.

- The formed regression equation show that sliding velocity and contact pressure has positively related and interaction between sliding velocity and contact pressure are negatively related. Model fits with 97.06\% between the observed actual experimental values and the predicted values.

- Optimal combination for wear rate was determined to be at lowest level of variables: $1.9 \mathrm{MPa}$ contact pressure, $0.64 \mathrm{~m} / \mathrm{san}$ sliding velocity and 10000 cycles.

- The ANOVA results revealed that estimated wear rate for optimum range was as follows: $0.0012<J$ (g/hour) $<0.005$ 
- The confirmation experiment proves that values of wear rate corresponds at optimum condition within the predicted 95\% confidence level.

\section{REFERENCES}

[1] M.H. Cho, S.J. Kim, D. Kim, H. Jang, Effects of Ingredients on Tribological Characteristics of a Brake Lining: An Experimental Case Study, Wear, vol. 258, iss. 11-12, pp. 1682-1687, 2005, doi: 10.1016/j.wear.2004.11.021

[2] C.V. Piyush, C. Rodica, B. Andrea, A. Pranesh, S. Giovanni, G. Stefano, Role of the Friction Layer In The High-Temperature Pin-On-Disc Study of a Brake Material, Wear, vol. 346-347 pp. 56-65, 2016, doi: 10.1016/j.wear.2015.11.004

[3] S.P. Jadhav, S.H .Sawant, A review paper: Development of Novel Friction Material for Vehicle Brake Pad Application to Minimize Environmental and Health Issues, Materials Today: Proceedings, vol. 19, no. 2, pp. 209-212, 2019, doi: 10.1016/j.matpr.2019.06.703

[4] K.W. Liew, U. Nirmal, Frictional Performance Evaluation of Newly Designed Brake Pad Materials, Materials \& Design, vol. 48, pp. 25-33, 2013, doi: 10.1016/j.matdes.2012.07.055

[5] F.H. Wang, Y. Liu, Mechanical and Tribological Properties of Ceramic-Matrix Friction Materials With Steel Fiber and Mullite Fiber, Materials \& Design, vol. 57, pp. 449-455, 2014, doi: 10.1016/j.matdes.2014.01.017

[6] X. Xingming, Y. Yan, B. Jiusheng, L. Lijian, F. Xuejun, Review on the Friction and Wear of Brake Materials, Advances in Mechanical Engineering, vol. 8, no. 5, pp. 1-10, 2016, doi: 10.1177/16878140 16647300

[7] P.S. Yadav, R. Purohit, A. Kothari, Study of Friction and Wear Behaviour of Epoxy/Nano $\mathrm{SiO}_{2}$ based Polymer Matrix Composites- A Review, Materials Today: Proceedings, vol. 18 , no. 7, pp. 55305539, 2019, doi: 10.1016/j.matpr.2019.07.666

[8] R.S. Rana, R. Purohit, A.K. Sharma, S. Rana, Optimization of Wear Performance of Aa 5083/10 Wt. \% SiCp Composites Using Taguchi Method, Procedia Materials Science, vol. 6, pp. 503-511, 2014, doi: 10.1016/j.mspro.2014.07.064

[9] R.K. Roy, A Primer on the Taguchi Method, Society of Manufacturing Engineers, 2010.

[10] J. Sudeepan, K. Kumar, T.K. Barman, P. Sahoo, Study of Friction and Wear of ABS/Zno Polymer Composite Using Taguchi Technique, Procedia Materials Science, vol. 6. pp. 391-400, 2014, doi: 10.1016/j.mspro.2014.07.050
[11] T. Madhusudhan, M.S. Kumar, Experimental Study on Wear Behaviour of SiC Filled Hybrid Composites Using Taguchi Method, International Journal of Mechanical Engineering and Technology, vol. 8, iss. 2, pp. 271-277, 2017.

[12] F. Kahraman, B. Sugözü, An Integrated Approach Based on the Taguchi Method and Response Surface Methodology to Optimize Parameter Design of Asbestos-Free Brake Pad Material, Turkish Journal of Engineering, vol. 3, no. 3, pp. 127-132, 2019, doi: 10.31127/tuje.479458

[13] Y. Luo, Z. Yang, Effect of Different-Condition Parameters on Frictional Properties of Non-Asbestos Phenolic Resin-Based Friction Material, Advances in Mechanical Engineering, vol. 9, iss. 5, pp.114, 2017, doi: 10.1177/1687814017710119

[14] M. Silva, L. Carneiro, J. Silva, I. Oliveira, F. Izario, H. Filho, Izário, C. Almeida, Oliveira, An Application of the Taguchi Method (Robust Design) to Environmental Engineering: Evaluating Advanced Oxidative Processes in Polyester-Resin Wastewater Treatment, American Journal of Analytical Chemistry, vol. 5, no. 23, pp. 828-837, 2014, doi: 10.4236/ajac.2014.5130 2

[15] S. N. Dhanalakshmi, N.Mohanasundararaju, P.G. Venkatakrishnan, V. Karthik, Optimization of

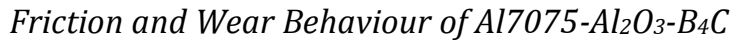
Metal Matrix Composites Using Taguchi Method, IOP Conference Series: Materials Science and Engineering, vol. 314, pp. 1-9, 2018, doi: 10.1088/1757-899X/314/1/012025

[16] H. Öktem, I. Uygur, G. Akincioğlu, S. Akincioğlu, Determination of Friction and Wear Behavior of Organic Dusts Reinforced with the Brake Pads by Using Taguchi Method, Proceedings on Engineering Sciences, vol. 1, no. 1, pp. 293-297, 2019, doi: 10.24874/PES01.01.037

[17] S.J. Kim, K.S. Kim, H. Jang, Optimization of manufacturing parameters for a brake lining using Taguchi method, Journal of Materials Processing Technology, vol. 136, no. 1-3, pp. 202208, 2003, doi: 10.1016/S0924-0136(03)00159-6

[18] B. Stojanovic, M. Babic, S.V. Gajević, J.M. Blagojević, Optimization of Wear Behaviour in Aluminium Hybrid Composites Using Taguchi Method, in 14th International Conference on Tribology, 13-15 May, 2015, SERBIATRIB 15, Belgrade, Serbian Tribology Society, pp. 81-86.

[19] J. Bao, Y. Yin, Z. Zhu, M. Tong, Y. Lu, Y. Peng, Wear Modalities And Mechanisms of the Mining NonAsbestos Composite Brake Material, Applied Composite Materials, vol. 20, pp. 331-339, 2013, doi: $10.1007 / s 10443-012-9269-4$

[20] X. Xiao, Y. Yin, J. Bao, L. Lu, X. Feng, Review on the Friction and Wear of Brake Materials, Advances 
in Mechanical Engineering, vol. 8, iss. 5, pp. 1-10, 2016, doi: $10.1177 / 1687814016647300$

[21] B.N. Ramesh, B. Suresha, Optimization of Tribological Parameters in Abrasive Wear Mode of Carbon-Epoxy Hybrid Composites, Materials \& Design, vol. 59, pp. 38-49, 2014, doi: 10.1016/j.matdes.2014.02.023

[22] T. Singh, A. Patnaik, B. Gangil, Thermal Stability Analysis of Nano-Particulate-Filled PhenolicBased Friction Composite Materials, Journal of Industrial Textiles, vol. 45, iss. 6, pp.1335-1349, 2016, doi: $10.1177 / 1528083714559568$

[23] E. Surojoa, D. Ariawan, R. Arsada, N. Muhayat, W.W. Raharjo, D.F. Smaradhana, Effect of Nitrile Butadiene Rubber (NBR) on Mechanical and Tribological Properties of Composite Friction Brakes, Tribology in Industry, vol. 41, no. 4, pp. 516-525, 2019, doi: 10.24874/ti.2019.41.04.05

[24] M. Eriksson, S. Jacobson, Tribological Surfaces of Organic Brake Pads, Tribology International, vol. 33, iss. 12, pp. 817-827, 2000, doi: 10.1016/S0301-679X(00)00127-4

[25] B. Jiusheng, Y.Yin, Z. Zhu, M. Tong, Y.Lu, Y.Peng, Wear Modalities and Mechanisms of the Mining
Non-asbestos Composite Brake Material, Applied Composite Materials, vol. 20, iss. 4, pp. 331-339, 2012, doi: 10.1007/s10443-012-9269-4

[26] S.V. Alagarsamy, M. Ravichandran, Investigations on tribological behaviour of AA7075-TiO2 composites under dry sliding conditions, Industrial Lubrication and Tribology, vol. 71, iss. 9, pp. 1064-1071, 2019, doi: 10.1108/ILT-012019-0003

[27] I. Mutlu. Investigation of Tribological Properties of Brake Pads by Using Rice Straw and Rice Husk Dust, Journal of Applied Sciences, vol. 9, no. 2, pp. 377-381, 2009, doi: 10.3923/jas.2009.377.381

[28] Y. Kumar, H. Singh, Application of Taguchi Method for Optimizing Material Removal Rate in Turning of En-47 Spring Steel, in 5th International and 26th All India Manufacturing Technology, Design and Research Conference, 12-14 December, 2014, AIMTDR 14, Guwahati, India, pp. 1-6

[29] A. Sharma, M. Garg, S. Singh, Taguchi Optimization of Tribological Properties of $\mathrm{Al} / \mathrm{Gr} / \mathrm{B}_{4} \mathrm{C}$ Composite, Industrial Lubrication and Tribology, vol. 67, no. 4, pp. 380-388, 2015, doi:10.1108/ILT-10-2014-0099 